\title{
Prevalence of Haemoproteus sp. in Galápagos blue-footed boobies: effects on health and reproduction
}

\author{
LARISA LEE-CRUZ ${ }^{1} * \dagger$, ANDREW A. CUNNINGHAM ${ }^{2}$, PAMELA MARTÍNEZ ${ }^{3}$, \\ MARILYN CRUZ ${ }^{3}$, SIMON J. GOODMAN ${ }^{1}$ and KEITH C. HAMER ${ }^{1}$ \\ ${ }^{1}$ School of Biology, University of Leeds, Leeds LS2 97T, UK \\ 2 Institute of Zoology, Zoological Society of London, Regent's Park, London NW $14 R Y, U K$ \\ ${ }^{3}$ Galápagos Genetics, Epidemiology and Pathology Laboratory, Galápagos National Park, Puerto Ayora, Galápagos \\ Islands, Ecuador
}

(Received 6 October 2015; revised 2 November 2015; accepted 6 November 2015)

\section{SUMMAR Y}

Populations of blue-footed boobies in the Galápagos Islands have declined by at least $50 \%$ compared with numbers recorded during the 1960s. Recently, concern has been expressed about potential adverse effects of introduced blood parasites; in particular, malarial parasites (i.e. Plasmodium sp.), which are frequently pathogenic and can cause mortality and morbidity in birds, and blood parasites of the genus Haemoproteus, which can reduce fitness. We screened blue-footed boobies at six breeding colonies within Galápagos for both genera of parasite. At two sites, we also investigated whether there was any relationship between infection status and physiological condition or breeding success. We found a high prevalence of Haemoproteus spp. in adults and chicks using PCR, although none was found on blood smears. We found no evidence of Plasmodium. Effects of parasitism on the condition of birds were limited. Also, there was no evidence that infection with Haemoproteus adversely affected breeding success or chick growth. Our results suggest that poor success of breeding birds was not strongly associated with Haemoproteus infection. However, regular colony monitoring and examination of dead birds are necessary to assess whether acute Haemoproteus infection might be responsible for some mortality, particularly of chicks.

Key words: emerging diseases, global biodiversity hotspot, invasive species, Haemoproteus, Sula nebouxii.

\section{INTRODUCTION}

The Galápagos archipelago in the eastern Pacific Ocean is a biodiversity hotspot supporting many endemic species and a diverse assemblage of marine birds (Bensted-Smith, 2002; Palacios et al. 2006). In contrast to many islands settled by humans, there is no evidence of local extinction of seabird species in Galápagos (Steadman, 2006). Nevertheless, some species show clear evidence of recent reductions in population sizes (Vargas et al. 2005; Jiménez-Uzcátegui et al. 2006; Anderson et al. 2008), making discerning the causes of such declines a conservation priority. The blue-footed booby (Sula nebouxii) breeds in Galápagos and on islands and headlands on the west coast of South and Central America and Mexico. The Galápagos subspecies ( $S$. nebouxii excisa) is both iconic and genetically distinct (Taylor et al. 2011) and was historically abundant, with probably $>10000$ breeding pairs in the 1960s (Nelson, 1978). However, it has apparently declined by more than $50 \%$ in the last decade, probably due to persistent low breeding frequency

* Corresponding author: School of Biology, University of Leeds, Leeds LS2 9JT, UK. E-mail:1leecruz@gmail.com $\dagger$ Present address: Laboratorio de Proteómica y Genotoxicología, Centro de Investigaciones Biológicas del Noroeste, S. C. Av. Instituto Politécnico Nacional No. 195, Col. Playa Palo de Santa Rita Sur, C. P. 23096, La Paz, BCS, México. and poor breeding success since around 1998, resulting in chronically low recruitment to the adult population (Anchundia et al. 2014). It has been suggested that this recent poor breeding is due to low local abundance of the species' principal prey (Pacific sardines Sardinops sagax). Other potential effects, such as impacts of introduced predators, were considered unlikely causes because breeding has been equally poor on islands with and without such factors (Anchundia et al. 2014). The effects of parasites, however, have not previously been considered.

Tourism and human immigration to Galápagos have increased dramatically over the past 30 years (Taylor et al. 2009), posing a high risk of novel pathogen introduction that could negatively impact native species (Wikelski et al. 2004; Kilpatrick et al. 2006; Bataille et al. 2009). One such threat is infection with blood parasites, particularly those such as Plasmodium and Haemoproteus (Parker et al. 2006; Levin et al. 2009) that can cause acute or chronic infections in the host. Infection with haemoparasites can cause anaemia, altering red blood cell (RBC) parameters and reducing oxygen transport (Booth and Elliott, 2002), affecting the overall physiological condition of infected individuals and their ability to perform energy-demanding activities such as raising chicks. Infected birds also mount an immune response which requires resources that are withdrawn from other activities, such as those 
involved in reproduction (Sheldon and Verhulst, 1996). Accordingly, several studies have shown that avian haemoparasites can adversely affect reproduction through lowering hatching success and/or reducing provisioning and growth rates of chicks and survival to fledging (Merino et al. 2000; Marzal et al. 2005; Tomás et al. 2007). Plasmodium has been strongly implicated in driving declines in populations of birds elsewhere (Atkinson et al. 1995). In contrast, even though Haemoproteus spp. have been known to cause disease and mortality in some avian hosts (Earle et al. 1992; Davidar and Morton, 1993; Garvin et al. 2003), they are generally regarded as benign, and multiple studies have not found any negative association between infection with Haemoproteus spp. and survival or reproduction of their host (e.g. Knutie et al. 2013; Kulma et al. 2014; Zylberberg et al. 2015).

Haemoparasites have recently been recorded in several seabird species within the Galápagos archipelago, including Galápagos penguin (Spheniscus mendiculus), swallowed-tailed gull (Creagrus furcatus), frigatebirds (Fregata spp.), Nazca booby (Sula grantii) and red-footed booby (Sula sula) (Padilla et al. 2006; Levin et al. 2009, 2011), but it is not known if infection has affected reproduction in any of these species. Blue-footed boobies are hosts to ticks (Argasidae and Ixodidae), louse flies (Hippoboscidae) and black flies (Simuliidae), all of which are potential vectors of haemoparasites (Valkiūnas, 2005). Also the mosquito Culex quinquefasciatus, which is found around human settlements in the Galápagos, is a known vector of avian Plasmodium (Bataille et al. 2009). Moreover, birds from one colony may disperse to other sites within the archipelago (Taylor et al. 2011), and so can potentially transport parasites between colonies. Here we assess if haemoparasites, specifically Haemoproteus sp. and Plasmodium sp., are present in adult blue-footed boobies at six breeding colonies in Galápagos. To evaluate if these haemoparasites could be implicated in the recent poor breeding of this species in Galápagos, we assess if, at two of these colonies, parasitic infection is associated with low body condition, altered haematological parameters of adults, or with low breeding success among those birds that initiated breeding. Low breeding success could also result from direct effects of parasites on chicks. Hence at two study sites, we also assess if parasites are present in chicks and, if so, whether they have detectable effects on growth, haematological parameters or survival to fledging.

\section{MATERIALS AND METHODS}

\section{Study sites and sampling}

To examine the prevalence of haemoparasite infection and impacts on haematological parameters, we obtained blood samples from adults at six breeding sites in Galápagos (Fig. 1) during the main breeding periods (April-September) of 2007 and 2008. Adults were captured at the nest site during the daytime using a telescopic pole with a brass noose, following Hamer et al. (2000); most adults had eggs or chicks at the time of sampling. Bill length was measured to the nearest $1 \mathrm{~mm}$ using metric tape, and body mass was measured using a spring balance $( \pm 10 \mathrm{~g})$ when captured. Sex was determined by examination of the iris and by vocalization (Nelson, 1978), and most birds were fitted with a numbered metal leg-ring to allow individual identification. Birds were handled for no longer than $5 \mathrm{~min}$ (and typically much less) and, upon release, all birds immediately returned to the nest-site from which they were captured and resumed normal behaviour.

To examine impacts of haemoparasites on breeding birds, we studied two focal breeding sites on the islands of San Cristobal and North Seymour (Fig. 1) in 2007 and 2008, respectively. In each case, all known nest sites occupied by adults were surveyed daily to record eggs or chicks, except for 12 nests in 2008 which were surveyed every 6 days. The extended laying periods of birds at each site precluded obtaining complete data on breeding success, but we were able to determine the fates of eggs laid and, if hatched, the growth and survival of chicks for most study pairs. For chicks, body mass was measured every 6 days using a spring balance $( \pm 5 \mathrm{~g}$ for chicks weighing up to $1 \mathrm{~kg}$; \pm 10 $\mathrm{g}$ for heavier chicks), and bill and ulna length were measured on each occasion to the nearest $1 \mathrm{~mm}$ using metric tape. Chicks were also blood-sampled to examine the prevalence of haemoparasites and potential impacts on haematological parameters and growth rates. Sexes of chicks were determined from blood samples using the PCR protocol of Fridolfsson and Ellegren (1999). Average ages of chicks when blood-sampled were $72 \pm 17$ days post-hatching at San Cristobal and $65 \pm 14$ days at North Seymour.

\section{Blood sampling}

Roughly 1-3 mL of blood were taken from the ulnar vein of each bird using a 23-gauge needle and syringe, collected in ethylenedimine tetraacetic acid (EDTA) tubes and stored on ice until taken to the laboratory, where they were stored at $4{ }^{\circ} \mathrm{C}$ for a maximum of $48 \mathrm{~h}$ before haematological parameters were measured. Fresh blood smears were made immediately after blood sampling using one drop of blood smeared on a slide. Birds were blood-sampled only once except for 30 adults at North Seymour that were sampled during both incubation and chick-rearing, to examine the temporal persistence of blood parasite infections. 


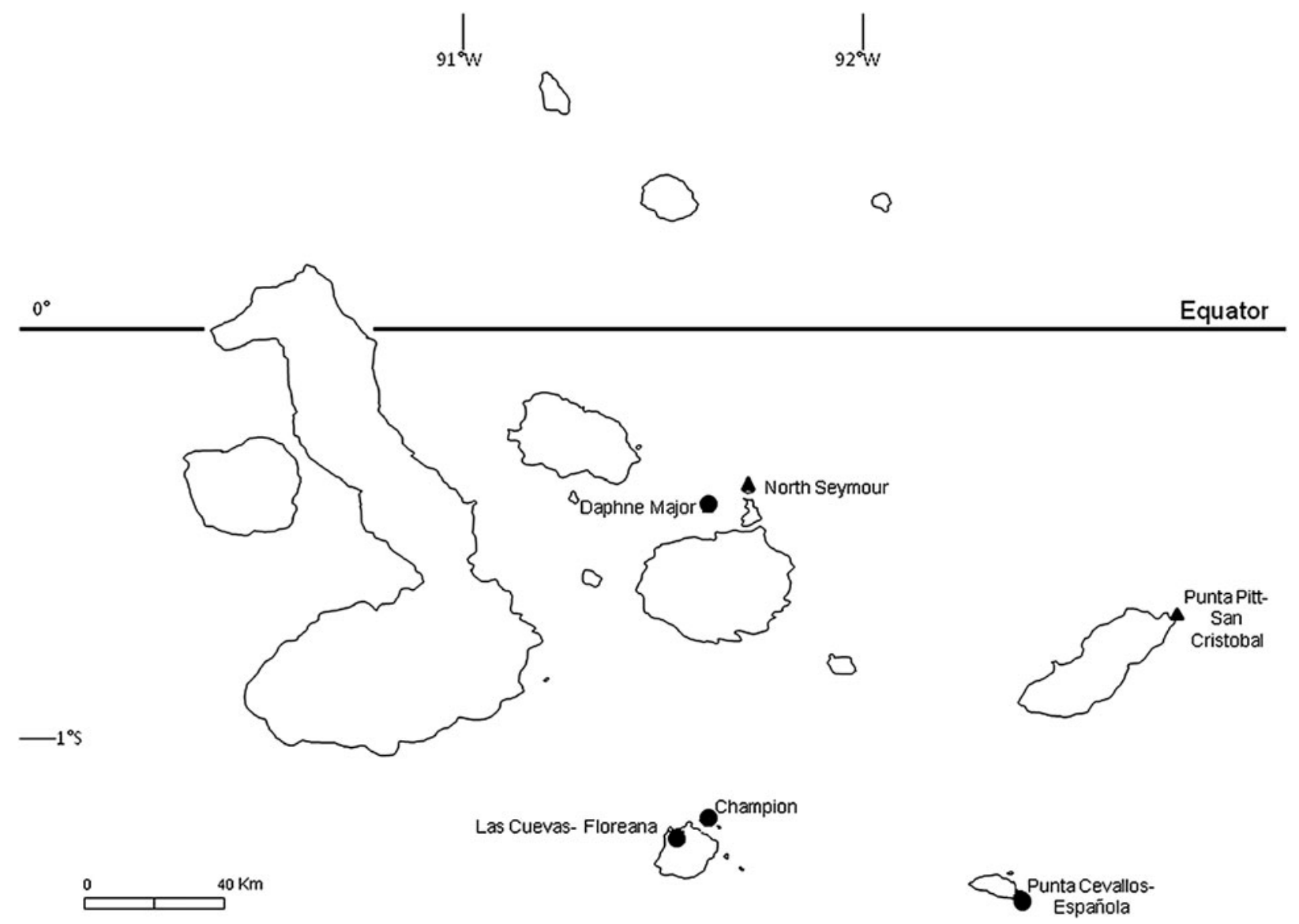

Fig. 1. Blue-footed booby breeding colonies sampled during 2007 and 2008. Focal colonies (see text) are marked with a other sampled colonies are marked with a

\section{Screening for parasites}

Parasite screening was performed by microscopic examination of blood smears, viewing 100 fields per smear using a $100 \times$ objective. We also screened for Haemoproteus spp. and Plasmodium spp. using a nested polymerase chain reaction (PCR) specific for detecting these genera (Waldenström et al. 2004). DNA was extracted from $30 \mu \mathrm{L}$ of EDTA-preserved blood according to Bermúdez-Humarán et al. (2002). We analysed 95 samples using the nested PCR method. For 154 samples we used the same nested PCR method with slightly modified primers as follows: nHaemNF (5'-CAACATATATTAA GAGAATTATGGA-3') and nHaemNR2 (5'-AA CAATATGTAGAGGAGTAACATAT-3') for the first PCR, and HaemF from Waldenström et al. (2004) and the new primer nHaemR2 (5'CATT ATCAGGATGWGCMTTAATGGTA-3') for the second PCR. PCR reactions were performed on 25 $\mu \mathrm{L}$ volumes using Flexi Go Taq (Promega), $0.2 \mathrm{~mm}$ of each dNTP (i.e. nucleotides), $3 \mathrm{~mm} \mathrm{MgCl}_{2}, 0.02$ mu of each primer and $2 \mu \mathrm{L}$ of template DNA. The first PCR was carried out with an initial denaturation step of $94^{\circ} \mathrm{C}$ for $3 \mathrm{~min}$, then 20 cycles with $94^{\circ} \mathrm{C}$ for $30 \mathrm{~s}, 50^{\circ} \mathrm{C}$ for $30 \mathrm{~s}$ and $72{ }^{\circ} \mathrm{C}$ for $45 \mathrm{~s}$, and a final extension at $72{ }^{\circ} \mathrm{C}$ for $10 \mathrm{~min}$. The second PCR followed the same thermal profile as the first but was run for 35 cycles with an annealing temperature of $52{ }^{\circ} \mathrm{C}$. PCR products were separated on a $2 \%$ agarose gel where the presence of a band of the expected size $(520 \mathrm{bp})$ indicated the presence of blood parasites. All PCR reactions were run with a negative control (ultrapure water; Sigma, UK) and a positive control (Plasmodium falciparum DNA). Positive PCR products from five different birds were sequenced using an ABI 3730 Automated Sequencer (PE Applied Biosystems Ltd., USA) at the NERC Molecular Genetics Facility, University of Sheffield. DNA sequences were compared with publicly available sequences in the GenBank database using BLASTN 2.2.4 (Altschul et al. 1997). No PCR products using the modified primers were sequenced, but two positives and one negative were used in each run.

\section{Haematology}

RBC counts were performed on a Neubauer haemocytometer using $20 \mu \mathrm{L}$ of blood diluted in $1000 \mu \mathrm{L}$ of Reese-Eckers dying solution (Campbell, 1995). Haemoglobin $(\mathrm{Hb})$ concentration was measured using the Hemocue system (Hemocue ${ }^{\circledR}$ Limited) 
based on absorbance of light. Mean corpuscular volume (MCV) was calculated using a standard formula (Campbell, 1995).

Total white blood cell (WBC) counts were performed on a Neubauer haemocytometer using $20 \mu \mathrm{L}$ of whole blood diluted in $380 \mu \mathrm{L}$ of ReeseEckers dying solution (Campbell, 1995). Leucocyte differentials were determined by examination of whole-blood smears made from fresh blood or from blood preserved in EDTA-tubes. All smears were air dried, fixed in methanol and stained with May-Grünwald-Giemsa stain within the first 24-48 h after preparation. If the quality of freshblood smears was poor, EDTA-preserved blood smears were used instead. EDTA does not affect leucocyte counts within the first $24-72 \mathrm{~h}$ for blood stored at $4{ }^{\circ} \mathrm{C}$ (Buttarello, 2004). Leucocyte differentials for each bird were determined by the percentage of heterophils, eosinophils, lymphocytes, monocytes and basophils in a total count of 100 leucocytes. Leucocyte counts were performed using a $100 \times$ objective lens, and were always performed by the same person (LLC).

\section{Statistical analyses}

To examine the potential factors associated with variation in infection at a site, we analysed prevalence of haemoparasitism at our two focal study sites using a generalized linear model (GLM) with binomial distribution of errors, with sex, breeding phase (incubation or chick-rearing) and their interaction as factors. We then applied a similar model to chicks with sex as a factor and age at sampling as a covariate. We also compared haemoparasite prevalence between adults and chicks at each site with a similar model using age-class (adult or chick) as a factor.

\section{Impact of parasitism on adults}

To examine effects of haemoparasitism on adult body mass, we used a linear model with infection status, sex, breeding phase and all two and three way interactions as factors and bill length as covariate. For North Seymour, where 30 adults had been sampled during both incubation and chick-rearing, we included bird identity as a random factor to account for birds sampled during both breeding phases.

We assessed the effect of blood parasites on haematological parameters of adults within each focal study colony separately. We fitted a linear model (LM), GLM, or generalized mixed-effects models (GLMM) with each haematological parameter in turn as the response variable. We used breeding phase, presence or absence of parasites (binary variable), sex and all two- and three-way interactions as factors for this analysis. For North Seymour, bird identity was again included as a random factor.
Overdispersion in GLMs was accounted for using a quasipoisson distribution of errors; in GLMMs we included an additional term based on the total number of observations to account for overdispersion, and therefore we removed bird identity if its standard deviation was less than that of the additional term. We added 1 to all lymphocyte count values to avoid log-transformation of any zero values. Nonsignificant interactions were removed sequentially.

\section{Timing of breeding}

We seldom observed egg-laying directly and so we used the median hatching date of chicks at each nest-site to measure timing of breeding. We estimated hatching dates of chicks by direct observation or, where hatching was not observed, from bill and ulna lengths calibrated against growth in firsthatched chicks of known age. Chick age was estimated from a logistic model fitted separately for bill and ulna lengths at each colony $(r>0.95$ in all cases). The two estimates for age of chick (i.e. age estimated from bill and ulna length models) were then averaged.

Adults often changed their parasitaemia status between incubation and chick-rearing (see 'Results' section) and so we used only adults blood-sampled during incubation at North Seymour to determine whether or not haemoparasites affected timing of breeding (few adults were sampled during incubation at San Cristobal). We used a Mann-Whitney test to compare median hatching dates of clutches incubated by adults with and without haemoparasites, analysing males and females separately. We also used a Kruskal-Wallis test to assess if median hatching date differed among nests with neither, one or both parents infected.

\section{Impact of parasitism on chicks}

Blue-footed booby chicks typically attain maximum mass at 65-70 days post-hatching (Drummond et al. 1991). To avoid including data during the period of pre-fledging mass recession, we therefore assessed the effect of haemoparasitism on body mass at the greatest age measured prior to 60 days post-hatching (Mean \pm SE: $59.4 \pm 0.56$ and $58.7 \pm 0.55$ days old at San Cristobal and North Seymour, respectively) using a linear model with haemoparasitism status, sex and their interaction as factors and chick age as a covariate.

To assess the effect of haemoparasitism on haematological parameters of chicks, we used LMs or GLMs with each haematological parameter in turn as the response variable, with blood infection status, sex and their interaction as factors, and with chick age at sampling as a covariate. Overdispersion in GLMs was accounted for using a quasipoisson distribution of errors and non-significant interactions were removed sequentially. 
Table 1. Number of blue-footed boobies sampled for parasite screening and percentage of birds with Haemoproteus sp. parasitaemia at six breeding sites in the Galápagos Islands

\begin{tabular}{|c|c|c|c|c|}
\hline \multirow[t]{2}{*}{ Site } & \multicolumn{2}{|c|}{ Males } & \multicolumn{2}{|c|}{ Females } \\
\hline & $N$ & Infected $(\% \pm \mathrm{CI})$ & $N$ & Infected $(\% \pm \mathrm{CI})$ \\
\hline Champion & 6 & $33.3 \pm 38$ & 6 & $33.3 \pm 38$ \\
\hline Daphne Major & 7 & $57.1 \pm 37$ & 5 & 0 \\
\hline Española & 6 & $83.3 \pm 28$ & 7 & $42.8 \pm 37$ \\
\hline Floreana & 7 & $28.6 \pm 33$ & 4 & 0 \\
\hline \multicolumn{5}{|l|}{ San Cristobal } \\
\hline Adults & 20 & $40 \pm 21$ & 26 & $26.9 \pm 17$ \\
\hline Chicks & 12 & $41.7 \pm 28$ & 17 & $64.7 \pm 23$ \\
\hline \multicolumn{5}{|l|}{ North Sevmour } \\
\hline Adults ${ }^{\mathrm{a}}$ & 51 & $54.9 \pm 14$ & 44 & $52.3 \pm 15$ \\
\hline Chicks & 15 & $66.7 \pm 24$ & 16 & $56.2 \pm 24$ \\
\hline
\end{tabular}

a 30 adults were sampled twice (i.e. during incubation and chick-rearing), thus $N$ refers to number of samples.

\section{Chick survival}

At San Cristobal all but two chicks alive at the end of the study period had fledged. At North Seymour, survival to fledging was not recorded, but chicks alive at the end of the study were on average $60 \pm 10$ (S.D.) days old, and chicks that died did so on average at $26 \pm 15$ (s.D.) days post-hatching. However, at least one chick died at 70 days of age, thus it is possible that survival to fledging was slightly overestimated for North Seymour. We compared the number of chicks that survived until the end of the study period (i.e. 0-2), between parasitaemic and non-parasitaemic adults. We analysed males and females separately at each colony. For birds at San Cristobal we used a Mann-Whitney test. For North Seymour, 15 adult pairs were blood-sampled during both incubation and chick-rearing, and so we used a mixed effects generalized linear model with Poisson distribution of errors; parasites, breeding phase and their interaction were used as factors, and bird ID was included as a random factor. For females alone, however, as the standard deviation of bird ID was close to zero, we used a generalized linear model without any random factor. The interaction between haemoparasitism and breeding phase was non-significant in all cases, thus we removed it from the models. We also compared if chick survival differed among nests where none, one or both adults were parasitaemic using a Kruskal-Wallis test. For birds at North Seymour we used PCR data of chick-rearing birds for this analysis.

All analyses were performed using $\mathrm{R}$ version 2.13.1 (R Development Core Team, 2008).

\section{RESULTS}

\section{Prevalence of haemoparasitism}

We obtained 249 blood samples from 159 adult bluefooted boobies at six breeding colonies in Galápagos and from 60 chicks at our two focal colonies.
Haemoparasite prevalence assessed using PCR of blood was high (33-83\%) at all sampled sites and in both adults and chicks (Table 1). The primers used are specific for Haemoproteus sp. and Plasmodium sp., with a high detection rate of Plasmodium compared with other assays (Waldenström et al. 2004). We sequenced five PCR products (GenBank accession numbers JF833060-JF833064), all of which were at least $99 \%$ similar to each other and at least 95\% similar to published Haemoproteus sequences in GenBank (closest match to Haemoproteus sp. LIN27, accession number EF380192.1). Also there was no suggestion of mixed infection (i.e. no double peaks in the chromatogram). Thus we assume that all parasites detected by PCR were Haemoproteus sp. In contrast, of the 249 blood smears screened, only one contained one parasite, probably belonging to the genus Leucocytozoon (G. Valkiūnas, personal communication 2014). No evidence of Plasmodium sp. infection was found. Prevalence of circulating Haemoproteus sp. infection did not differ significantly between males and females in adults or chicks, or between incubation and chick-rearing for adults at either of our two focal colonies (Table 1; $\mathrm{LRT}_{1}$, $P \geq 0.1$ in all cases). Chicks were marginally more likely to be parasitaemic than adults at San Cristobal $\left(\mathrm{LRT}_{1}=3.73, P=0.05\right)$ but not at North Seymour $(P=0.52)$. Adults sampled twice at North Seymour commonly changed the parasitaemia status; of 20 birds parasitaemic during incubation, 15 (75\%) were PCR-negative for haemoparasites during chickrearing, while of 10 birds that were apparently free of circulating parasites during incubation, $7(70 \%)$ were PCR-positive during chick-rearing.

\section{Impact of parasitism on adults}

The presence of blood parasites had no detectable effect on body mass or on any haematological variables in the birds sampled at San Cristobal (Table 2). At North Seymour, parasitaemia had no 
Table 2. LM, GLM or GLMM of the presence of Haemoproteus sp. parasitaemia on physiological parameters of blue-footed booby adults at two breeding colonies in the Galápagos Islands

\begin{tabular}{|c|c|c|c|c|c|c|}
\hline Site & Parameter & Estimate & S.E. & $F$ or LRT & D.F. & $P$ \\
\hline \multicolumn{7}{|c|}{ San Cristobal } \\
\hline & Body mass & 15.21 & 38.86 & 0.15 & 1,36 & 0.70 \\
\hline & $\mathrm{Hb}$ & -0.51 & 0.51 & 1.03 & 1,39 & 0.31 \\
\hline & $\mathrm{MCV}^{\mathrm{a}}$ & -0.06 & 0.09 & 0.44 & 1,39 & 0.51 \\
\hline & WBC & -0.52 & 0.63 & 0.68 & 1,38 & 0.41 \\
\hline & Heterophil & 1.90 & 3.62 & 0.27 & 1,38 & 0.60 \\
\hline & Eosinophil & -0.10 & 0.11 & 0.78 & 1,39 & 0.38 \\
\hline & Lymphocyte & 0.18 & 0.21 & 0.75 & 1,39 & 0.39 \\
\hline & $\mathrm{H} / \mathrm{L}_{\text {ratio }}{ }^{\mathrm{a}}$ & -0.06 & 0.23 & 0.07 & 1,37 & 0.80 \\
\hline \multicolumn{7}{|c|}{ North Seymour } \\
\hline & $\begin{array}{l}\text { Body mass } \\
\mathrm{Hb}\end{array}$ & $\begin{array}{r}45.69 \\
0.10\end{array}$ & $\begin{array}{r}26.26 \\
0.23\end{array}$ & $\begin{array}{l}3.12 \\
0.18\end{array}$ & 1 & $\begin{array}{l}0.08 \\
0.67\end{array}$ \\
\hline & $\begin{array}{l}\mathrm{HD} \\
\mathrm{MCV}^{\mathrm{a}}\end{array}$ & 0.009 & $\begin{array}{l}0.23 \\
0.06\end{array}$ & $\begin{array}{l}0.18 \\
0.02\end{array}$ & $\begin{array}{l}1 \\
1\end{array}$ & $\begin{array}{l}0.67 \\
0.88\end{array}$ \\
\hline & WBC & -0.24 & 0.55 & 0.20 & 1 & 0.65 \\
\hline & Heterophil & -0.10 & 0.05 & 3.55 & 1 & 0.06 \\
\hline & Eosinophil & 0.03 & 0.05 & 0.40 & 1 & 0.53 \\
\hline & \multicolumn{6}{|l|}{ Lymphocyte } \\
\hline & Parasites:sex & -0.60 & 0.25 & 5.69 & 1 & 0.02 \\
\hline & Parasites:breeding phase & -0.79 & 0.25 & 9.26 & 1 & 0.002 \\
\hline & \multicolumn{6}{|l|}{$\mathrm{H} / \mathrm{L}$ ratio ${ }^{\mathrm{a}}$} \\
\hline & Parasites:sex & 0.78 & 0.39 & 5.76 & 1 & 0.02 \\
\hline
\end{tabular}

Breeding phase, sex, presence of parasites and all interactions were used as factors. Non-significant interactions were removed sequentially. $\mathrm{Hb}$, haemoglobin; MCV, mean corpuscular volume; WBC, total white blood cell count.

a Variable was ln-transformed.

detectable effect on MCV or Hb but had marginally non-significant effects on body mass $(P=0.08)$ and heterophil count $(P=0.06)$; PCR-positive birds tended to be heavier and with a lower heterophil count than PCR-negative birds. Lymphocyte count and $\mathrm{H} / \mathrm{L}$ ratio were affected by the presence of parasitaemia, although there was an opposite effect in males and females (Table 2).

\section{Timing of breeding}

Hatching dates did not differ significantly between clutches incubated by parasitaemic and non-parasitaemic females or males at North Seymour $(P \geq 0.2$ in both cases), and did not differ among nests where neither parent, one or other parent, nor both parents were parasitaemic $\left(\chi^{2}=0.85\right.$, D.F. $\left.=2, P=0.65\right)$.

\section{Impact of parasitism on chicks}

Chick body mass at 60 days old did not differ in relation to the PCR result obtained from either their female or male parent at North Seymour (female, $t_{11}=1.43, P=0.18$; male, $\left.t_{8}=-0.12, P=0.91\right)$, was marginally lower for chicks at San Cristobal for which the male parent was PCR-positive at the time of blood-sampling, $\left(t_{11}=-2.0, P=0.07\right)$, but did not differ in relation to the blood PCR-status of their female parent $\left(t_{11}=1.04, P=0.32\right)$. Also, chick body mass at 60 days old did not differ between chicks that were parasitaemic and those that were not at the time of blood-sampling (all $P>0.05)$. Of the haematological parameters measured, only $\mathrm{H} / \mathrm{L}$ ratio was apparently affected by nestling parasitaemia (San Cristobal: parasites-sex interaction, $F_{1,21}=6.23, P=0.02$; North Seymour: parasites $\left.F_{1,27}=4.06, P=0.05\right)$. This effect was, however, mainly attributable to the haematological results of two chicks at San Cristobal and one chick at North Seymour that had particularly high $\mathrm{H} / \mathrm{L}$ ratios.

\section{Chick survival}

No effect of adult blood PCR-status was found on chick survival at San Cristobal (females, $W=20.5$, $P=0.33$; males, $W=27.5, \quad P=0.59)$ or North Seymour (females, $\mathrm{LRT}_{1}=0.57, P=0.45$; males, $\left.\mathrm{LRT}_{1}=0.04, P=0.83\right)$. Also, chick survival did not differ among nests where neither, one or other, nor both parents were PCR-positive (San Cristobal: $\chi^{2}=1.34, \quad$ D.F. $=2, \quad P=0.51 ; \quad$ North Seymour: $\chi^{2}=3.69$, D.F. $=2, P=0.16$ ).

\section{DISCUSSION}

Blood parasites were detected in blue-footed boobies from all of the six sites sampled. At the two focal breeding colonies, the prevalence of Haemoproteus sp. parasitaemia was high in both adults and chicks. This parasite was, however, detected only using PCR and was not found on microscopical 
examination of blood smears, which is consistent with low levels of parasitaemia (Bentz et al. 2006). Also, it is possible that in some cases our PCR assay detected free DNA rather than viable parasites. Only one parasite, probably Leucocytozoon sp., was found on examination of the blood smears. Importantly, no evidence of Plasmodium sp. infection was found from either microscopy or PCR of blood samples. We do not know of any case of Plasmodium sp. infection in boobies. However, given that mosquitoes can feed on seabirds in the Galápagos (Anderson and Fortner, 1988) and that Plasmodium has been found in several bird species in the archipelago (Levin et al. 2013), there is potential of transmission of this parasite to Galápagos blue-footed boobies.

No differences in heterophil counts, eosinophil counts or in total WBC counts were detected between birds with and without parasitaemia. Increases in these haematological parameters can occur in response to high levels of Haemoproteus infection (Ots and Hõrak, 1998; Garvin et al. 2003; Dunn et al. 2013). Our haematology and PCR results, therefore, concur, suggesting that levels of parasitaemia were low in blue-footed boobies with negligible effects on circulating leucocytes. It is possible, however, that in our study birds negative for parasitaemia at the time of blood-sampling were not uninfected, but harboured only non-circulating, intra-endothelial tissue stages of Haemoproteus (Valkiūnas et al. 2004). For instance, infections in which the life cycle of the parasite is not completed within the host can occur, resulting in the absence of gametocytes in the host's circulating blood (Valkiūnas et al. 2014). This might also explain why the initial PCR-status of sampled adults at North Seymour during incubation was not a reliable indicator of parasitaemia at the time of the second blood-sampling period during chick-rearing. We did not analyse any other tissue apart from blood. Histological examination of naturally dead birds and more frequent, repeated blood sampling of individual birds would be required to identify infection by Haemoproteus reliably in Galápagos blue-footed boobies.

Based on our data, parasitaemia in adults affected only lymphocyte counts and $\mathrm{H} / \mathrm{L}$ ratio, and only at North Seymour. Also, at this colony adults had similar prevalence of parasitaemia as chicks, whereas on San Cristobal the prevalence was significantly higher in chicks than in adults. Chicks are permanently exposed to biting vectors and are naïve to Haemoproteus infection; thus, it is common for them to reach higher infection loads, prevalences and durations of parasitaemia than adults (Merino and Potti, 1995; Merino, 2010). This apparent association between parasitaemia and haematological parameters and higher parasite prevalence only in adults at North Seymour may be related to overall poor condition of these birds compared with those at San Cristobal (adults at North Seymour were on average 14\% lighter than those on San Cristobal). However, there could be other factors not detected by our study that affected adults' physiological fitness on North Seymour.

We found no evidence of any association between Haemoproteus sp. parasitaemia and reproductive output at either focal breeding colony. Also, in contrast to other studies in which high levels of lymphocytes, heterophils, eosinophils and $\mathrm{H} / \mathrm{L}$ ratio have been associated with haemoparasites in nestlings (Garvin et al. 2003; Soler et al. 2003; Norte et al. 2009), we did not find strong effects of parasitaemia on blood parameters on chicks at either colony. Only the $\mathrm{H} / \mathrm{L}$ ratio appeared to be affected by parasitaemia, but this was due to two and one chick at San Cristobal and North Seymour, respectively, with particularly high $\mathrm{H} / \mathrm{L}$ ratios. These three chicks had very low lymphocyte counts, two had a very high heterophil count and one had a particularly low body mass compared with other chicks its age. Even though it is possible that these leucocyte counts resulted from the Haemoproteus sp. infection detected in these chicks, other causes such as other pathogens, poor provisioning or sibling interactions cannot be ruled out (Maxwell, 1993; Parejo et al. 2007).

Several studies have reported the presence of blood parasites in wild birds in Galápagos (Padilla et al. 2006; Santiago-Alarcon et al. 2010; Levin et al. 2011), including one report of the malarial parasite Plasmodium sp. in the Galápagos penguin (Levin et al. 2009), and there is great interest in the threat that such pathogens might present to the endemic Galápagos avifauna (Miller et al. 2001; Wikelski et al. 2004). Here we found that Haemoproteus sp. is prevalent in blue-footed boobies by PCR, but not by microscopy. This has also been the case for Plasmodium parasites in the Galápagos, with migratory birds passing through the archipelago being a possible reservoir of this pathogen (Levin et al. 2013). We obtained DNA sequences of parasites isolated from five different adult birds. The closest match to all five sequences was to a Haemoproteus sp. LIN 27 belonging to a chestnut bunting (Emberizidae) (Ishtiaq et al. 2007). Our sequences were also included in a phylogenetic analysis of Haemoproteus spp., and the results showed that the five sequences were closely related to Haemoproteus balmorali (see sequences for $S$. nebouxii in phylogenetic tree in Levin et al. 2011), found in members of the Turdidae and Muscicapidae families (Hellgren et al. 2007). These parasites belong to the Parahaemoproteus subgenus which is found in passerines. Thus, it is possible that Parahaemoproteus parasites are transmitted to blue-footed boobies in Galápagos from passerine hosts common around blue-footed boobies' nests, 
such as finches or mockingbirds. Haemoproteus and Parahaemoproteus are two subgenera that form distinct clades within the genus Haemoproteus (Valkiūnas et al. 2010). Haemoproteus and Parahaemoproteus are transmitted by hippoboscid flies (Hippoboscidae) and biting midges (Culicoides, Ceratopogonidae), respectively. Hippoboscid flies are ectoparasites of passerines and marine birds in Galápagos (Levin et al. 2011; Štefka et al. 2011), but the role of biting midges as vectors of Haemoproteus spp. has not be confirmed in Galápagos.

Anchundia et al. (2014) suggested chronic breeding failure of blue-footed boobies in the Galápagos may be due to lack of their preferred prey, sardines. They pointed out that there is little evidence to suggest infectious disease as a possible cause of the observed decline. We found parasitaemic birds in all six colonies sampled, but results from our two focal colonies showed negligible impact on reproductive output in spite of high prevalence of Haemoproteus spp. parasitaemia in adults and chicks. No impact of Haemoproteus on survival or reproduction has been reported for several bird species (e.g. Knutie et al. 2013, de Jong et al. 2014). Moreover, higher survival and reproduction has been related to Haemoproteus infection (Zylberberg et al. 2015). The authors of this study suggest that infected individuals may not invest in immune defence in the case of less virulent pathogens, if such investment would result in reduced lifetime reproductive success. This could also be the case on long-lived birds such as many marine birds. Additionally, long embryonic development in seabirds may allow for a strong immune system better able to fight infection (Ricklefs, 1992).

Chick survival at our two focal colonies was not related to parasitaemia. In contrast, it was closely associated with variation in growth: chicks that survived were much heavier from the third week posthatching compared with age-specific body masses of chicks that died before fledging (GLMM, chick age-survival interaction, San Cristobal, $\mathrm{LRT}_{1}=$ 18.25, $P<0.0001$; North Seymour, LRT $=13.23$, $P=0.0003$, Fig. 2). Chick growth at our study sites was also poor compared with that reported for chicks elsewhere. For instance, chicks 45 days old at San Cristobal and North Seymour had body masses roughly 30\% lower compared with chicks the same age on Isla de Lobos de Tierra, Perú (Velando, 2002). This difference was especially marked for chicks at North Seymour, which were lighter than those in San Cristobal, and also compared with chicks in Mexico (Drummond et al. 1991) and to chicks measured at 13 sites in the Galápagos in 1981 (Ricklefs et al. 1984). These data support the hypothesis that the low breeding success of this species in Galápagos is related at least partly to scarce prey availability.

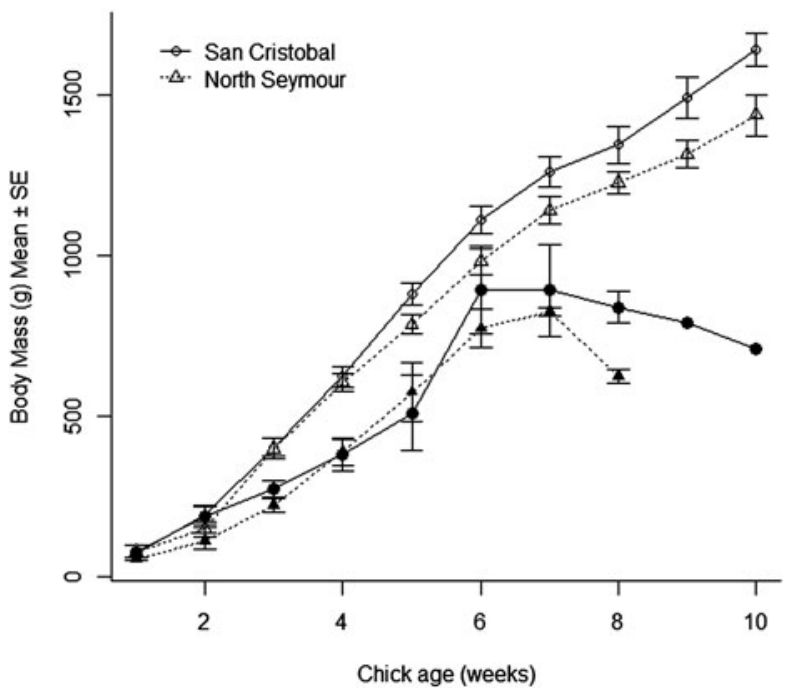

Fig. 2. Body mass of blue-footed booby chicks in relation to age of chicks that survived (open symbols) and chicks that died (filled symbols) at two breeding colonies in the Galápagos Islands.

Overall, our results suggest that the decline in blue-footed boobies in Galápagos is not strongly associated with Haemoproteus infection and we did not detect any infection with Plasmodium spp. malarial parasites. However we found a parasite, probably Leukocytozoon, on one of the smears, and future studies should use molecular methods to elucidate the prevalence of infection with this parasite in blue-footed boobies. This would be relevant as concurrent infections can be more harmful than single ones (Marzal et al. 2008). We did find a difference in body condition between birds in San Cristobal and North Seymour, with the latter generally being in poorer condition. Birds in poor condition can be more vulnerable to infectious diseases (Lochmiller and Deerenberg, 2000, Alonso-Alvarez and Tella, 2001) and we also found higher Haemoproteus prevalence in both adults and chicks at North Seymour. There was, however, no significant difference between the two islands in breeding success of birds. Parasitic infection and poor body condition can have synergistic effects, which can impact on population dynamics (Beldomenico and Begon, 2010). Regular monitoring of the bluefooted booby population in the Galápagos archipelago is needed to assess if it continues to decline and if so, to help identify the causes.

\section{ACKNOWLEDGEMENTS}

We thank Sarah-L. Smith, Alberto Vélez, and Pablo Mejía for their help in the field, and David Anderson, Virna Cedeño, Washington Tapia, David Vizuete, Miton Mora, Efraín García and Nelson García for logistical support and advice. PCR products were sequenced at the NERC Molecular Genetics Facility, University of Sheffield. We also thank two anonymous reviewers for their comments on a previous version of this manuscript. 


\section{F INA NCIAL S UPPOR'T}

This study was funded by Consejo Nacional de Ciencia y Tecnología, México, postgraduate studies scholarship granted to L.L.C., and carried out in collaboration with the Galápagos National Park Service, and the Galápagos Genetics, Epidemiology and Pathology Laboratory, with support from the UK Government (DEFRA Darwin Initiative Grants 162-12-17 and EIDPO15 to S.J.G. and A.A.C.

\section{CONFLICT OF INTEREST}

None.

\section{ETHICAL STANDARDS}

The authors assert that all procedures including blood-sampling protocols contributing to this work comply with the ethical standards of the Galápagos National Park Service.

\section{REFERENCES}

Alonso-Alvarez, C. and Tella, J. L. (2001). Effects of experimental food restriction and body-mass changes on the avian $\mathrm{T}$-cell mediated immune response. Canadian Fournal of Zoology 79, 101-105.

Altschul, S. F., Madden, T. L., Schaffer, A. A., Zhang, J., Zhang, Z., Miller, W. and Lipman, D. J. (1997). Gapped BLAST and PSIBLAST: a new generation of protein database search programs. Nucleic Acids Research 25, 3389-3402.

Anchundia, D., Huyvaert, K. P. and Anderson, D. J. (2014). Chronic lack of breeding by Galápagos blue-footed boobies and associated population decline. Avian Conservation and Ecology 9, 6.

Anderson, D. J. and Fortner, S. (1988). Waved albatross egg neglect and associated mosquito ectoparasitism. The Condor 90, 727-729.

Anderson, D. J., Huyvaert, K. P., Awkerman, J. A., Proaño, C. B., Milstead, W. B., Jiménez-Uzcátegui, G., Cruz, S. and Grace, J. K. (2008). Population status of the critically endangered waved albatross (Phoebastria irrorata), 1999 to 2007. Endangered Species Research 5, 185-192. Atkinson, C. T., Woods, K. L., Dusek, R. J., Sileo, L. S. and Iko, W. M. (1995). Wildlife disease and conservation in Hawaii: pathogenicity of avian malaria (Plasmodium relictum) in experimentally infected Iiwi (Vestiaria coccinea). Parasitology 111 (Suppl.), S59-S69.

Bataille, A., Cunningham, A. A., Cedeño, V., Cruz, M., Eastwood, G., Fonseca, D. M., Causton, C. E., Azuero, R., Loayza, J., Martinez, J. D. C. and Goodman, S. J. (2009). Evidence for regular ongoing introductions of mosquito disease vectors into the Galápagos Islands. Proceedings of the Royal Society of London B: Biological Sciences 276, 3769-3775.

Beldomenico, P. M. and Begon, M. (2010). Disease spread, susceptibility and infection intensity: vicious circles? Trends in Ecology and Evolution $25,21-27$.

Bensted-Smith, R. (ed.) (2002). A Biodiversity vision for the Galapagos Islands. Charles Darwin Foundation and World Wildlife Fund, Puerto Ayora, Galapagos.

Bentz, S., Rigaud, T., Barroca, M., Martin-Laurent, F., Bru, D., Moreau, J. and Faivre, B. (2006). Sensitive measure of prevalence and parasitaemia of haemosporidia from European blackbird (Turdus merula) populations: value of PCR-RFLP and quantitative PCR. Parasitology 133, 685-692.

Bermúdez-Humarán, L. G., García-García, A., Leal-Garza, C. H., Riojas-Valdes, V. M., Jaramillo-Rangel, G. and Montes-de-OcaLuna, R. (2002). Molecular sexing of monomorphic endangered Ara birds. Fournal of Experimental Zoology 292, 677-680.

Booth, C. E. and Elliott, P. F. (2002). Hematological responses to hematozoa in North American and neotropical songbirds. Comparative Biochemistry and Physiology Part A: Molecular and Integrative Physiology 133, 451

Buttarello, M. (2004). Quality specification in haematology: the automated blood cell count. Clinica Chimica Acta 346, 45-54.

Campbell, T. W. (1995). Avian Hematology and Cytology. Iowa State University Press, Iowa, USA.
Davidar, P. and Morton, E. S. (1993). Living with parasites: prevalence of a blood parasites and its effect on survivorship in the purple martin. Auk 110, 109-116.

de Jong, M. E., Fokkema, R. W., Ubels, R., van der Velde, M. and Tinbergen, J. M. (2014). No evidence for long-term effects of reproductive effort on parasite prevalence in tits Parus major. Fournal of Avian Biology 45, 179-186.

Drummond, H., Osorno, J. L., Torres, R., García-Chavelas, C. and Merchant Larios, H. (1991). Sexual size dimorphism and sibling competition: implications for avian sex ratios. American Naturalist 138, 623-641. Dunn, J. C., Goodman, S. J., Benton, T. G. and Hamer, K. C. (2013). Avian blood parasite infection during the non-breeding season: an overlooked issue in declining populations?. BMC Ecology 13, 30.

Earle, R. A., Bastianello, S. S., Bennett, G. F. and Krecek, R. C. (1992). Histopathology and morphology of the tissue stages of Haemoproteus columbae causing mortality in Columbiformes. Avian Pathology 22, 67-80.

Fridolfsson, A. K. and Ellegren, H. (1999). A simple and universal method for molecular sexing of non-ratite birds. Fournal of Avian Biology 30, 116-121.

Garvin, M. C., Homer, B. L. and Greiner, E. C. (2003). Pathogenicity of Haemoproteus danilezwskyi Kruse 1890 in blue jays (Cyanocitta cristata). Fournal of Wildlife Diseases 39, 161-169.

Hamer, K. C., Phillips, R. A., Wanless, S., Harris, M. P. and Wood, A. G. (2000). Foraging ranges, diets and feeding locations of gannets in the North Sea: evidence from satellite telemetry. Marine Ecology Progress Series 200, 257-264

Hellgren, O., Križanauskiene, A., Valkiūnas, G. and Bensch, S. (2007). Diversity and phylogeny of mitochondrial cytochrome B lineages from six morphospecies of avian Haemoproteus (Haemosporida: Haemoproteidae). Fournal of Parasitology 93, 889-896.

Ishtiaq, F., Gering, E., Rappolel, J. H., Rahmani, A. R., Jhala, Y. V., Dove, C. J., Milensky, C., Olson, S. L., Peirce, M. A. and Fleischer, R. C. (2007). Prevalence and diversity of avian hematozoan parasites in Asia: a regional survey. Fournal of Wildlife Diseases 43, 382-398.

Jiménez-Uzcátegui, G., Milstead, B., Márquez, C., Zabala, J., Buitrón, P., Llerena, A. and Fessl, B. (2006). Galápagos vertebrates: endangered status and conservation actions. Galápagos Report 2007, 104-110. Kilpatrick, A. M., Daszak, P., Goodman, S. J., Rogg, H., Kramer, L. D., Cedeño, V. and Cunningham, A. A. (2006). Predicting pathogen introduction: West Nile Virus spread to Galápagos. Conservation Biology 20, 1224-1231.

Knutie, S. A., Waite, J. L. and Clayton, D. H. (2013). Does avian malaria reduce fledging success: an experimental test of the selection hypothesis. Evolutionary Ecology 27, 185-191.

Kulma, K., Low, M., Bensch, S. and Qvarnström, A. (2014). Malariainfected female collared flycatchers (Ficedula albicollis) do not pay the cost of late breeding. PLoS ONE 9, e85822.

Levin, I. I., Outlaw, D. C., Vargas, F. H. and Parker, P. G. (2009). Plasmodium blood parasite found in endangered Galapagos penguins (Spheniscus mendiculus). Biological Conservation 142, 3191

Levin, I. I., Valkiūnas, G., Santiago-Alarcon, D., Lee Cruz, L., Iezhova, T. A., O'Brien, S. L., Hailer, F., Dearborn, D. Schreiber, E. A., Fleischer, R. C., Ricklefs, R. E. and Parker, P. G. (2011). Hippoboscid-transmitted Haemoproteus parasites (Haemosporida) infect Galapagos Pelecaniform birds: evidence from molecular and morphological studies, with a description of Haemoproteus iwa. International Fournal for Parasitology 41, 1019-1027.

Levin, I. I., Zwiers, P., Deem, S. L., Geest, E. A., Higashiguchi, J. M., Iezhova, T. A., Jiménez-Uzcátegui, G., Kim, D. H., Morton, J. P., Perlut, N. G., Renfrew, R. B., Sari, E. H. R., Valkiūnas, G. and Parker, P. G. (2013). Multiple lineages of avian malaria parasites (Plasmodium) in the Galápagos Islands and evidence for arrival via migratory birds. Conservation Biology 27, 1366-1377.

Lochmiller, R. L. and Deerenberg, C. (2000). Trade-offs in evolutionary immunology: just what is the cost of immunity? Oikos 88, 87-98.

Marzal, A., De Lope, F., Navarro, C. and Møller, A. P. (2005). Malarial parasites decrease reproductive success: an experimental study in a passerin bird. Oecologia $142,541-545$.

Marzal, A., Bensch, S., Reviriego, M., Balbontin, J. and De Lope, F. (2008). Effects of malaria double infection in birds: one plus one is not two. Fournal of Evolutionary Biology 21, 979-987.

Maxwell, M. H. (1993). Avian blood leucocyte responses to stress. Worlds Poultry Science F 49, 34-43.

Merino, S. (2010). Immunocompetence and parasitism in nestlings from wild populations. The Open Ornithology fournal 3, 27-32.

Merino, S. and Potti, J. (1995). High prevalence of hematozoa in nestlings of a passerine species, the pied flycatcher (Ficedula hypoleuca). Auk 112, 1041-1043. 
Merino, S., Moreno, J., Sanz, J. J. and Arriero, E. (2000). Are avian blood parasites pathogenic in the wild? A medication experiment in blue tits (Parus caeruleus). Proceedings of the Royal Society of London B: Biological Sciences 267, 2507-2510.

Miller, G. D., Hofkin, B. V., Snell, H., Hahn, A. and Miller, R. D. (2001). Avian malaria and Marek's disease: potential threats to Galapagos Penguins Spheniscus mendiculus. Marine Ornithology 29, 43-46.

Nelson, J. B. (1978). The Sulidae: Gannets and Boobies. Oxford University Press, Oxford, UK.

Norte, A. C., Araújo, P. M., Sampaio, H. L., Sousa, J. P. and Ramos, J. A. (2009). Haematozoa infections in a Great Tit Parus major population in Central Portugal: relationships with breeding effort and health. Ibis 151, 677-688.

Ots, I. and Hõrak, P. (1998). Health impact of blood parasites in breeding great tits. Oecologia 116, 441-448.

Padilla, L. R., Whiteman, N. K., Merkel, J., Huyvaert, K. P. and Parker, P. G. (2006). Health assessment of seabirds on Isla Genovesa, Galápagos Islands. Ornithological Monographs 60, 86-97.

Palacios, D. M., Bograd, S. J., Foley, D. G. and Schwing, F. B. (2006). Oceanographic characteristics of biological hot spots in the North Pacific: a remote sensing perspective. Deep Sea Research Part II: Topical Studies in Oceanography 53, 250-269.

Parejo, D., Silva, N. and Avilés, J. M. (2007). Within-brood size differences affect innate and acquired immunity in roller Coracias garrulus nestlings. Fournal of Avian Biology 38, 717-725.

Parker, P. G., Whiteman, N. K. and Miller, R. E. (2006). Conservation Medicine on the Galápagos Islands: partnerships among behavioral, population, and veterinary scientist. Auk 123, 625-638.

R Development Core Team (2008). R: A Language, Environment for Statistical Computing. R Foundation for Statistical Computing, Vienna. Ricklefs, R. E. (1992). Embryonic development period and the prevalence of avian blood parasites. Proceedings of the National Academy of Sciences of the United States of America 89, 4722-4725.

Ricklefs, R. E., Duffy, D. C. and Coulter, M. (1984). Weight gain of blue-footed booby chicks: an indicator of marine resources. Ornis Scandinavica 15, 162.

Santiago-Alarcon, D., Outlaw, D. C., Ricklefs, R. E. and Parker, P. G. (2010). Phylogenetic relationships of haemosporidian parasites in New World Columbiformes, with emphasis on the endemic Galapagos dove. International fournal for Parasitology 40, 463-470.

Sheldon, B. C. and Verhulst, S. V. (1996). Ecological immunology: costly parasite defences and trade-offs in evolutionary ecology. Trends in Ecology and Evolutionl 11, 317-321.

Soler, J. J., Neve, L. D., Pérez Contreras, T., Soler, M. and Sorci, G. (2003). Trade-off between immunocompetence and growth in magpies: an experimental study. Proceedings of the Royal Society of Londond B: Biological Sciences 270, 241-248.

Steadman, D. W. (2006). Extinction and Biogeography in Tropical Pacific Birds. University of Chicago Press, Chicago, Illinois, USA.
Štefka, J., Hoeck, P. E. A., Keller, L. F. and Smith, V. S. (2011). A hitchhikers guide to the Galápagos: co-phylogeography of Galápagos mockingbirds and their parasites. BMC Evolutionary Biology 11, 284.

Taylor, J. E., Hardner, J. and Stewart, M. (2009). Ecotourism and economic growth in the Galapagos: an island economy-wide analysis. Environment and Development Economics 14, 139-162.

Taylor, S. A., Maclagan, L., Anderson, D. J. and Friesen, V. L. (2011). Could specialization to cold-water upwelling systems influence gene flow and population differentiation in marine organisms? A case study using the blue-footed booby, Sula nebouxii. Fournal of Biogeography 38, 883-893. Tomás, G., Merino, S., Moreno, J., Morales, J. and Martínez-de 1a Puente, J. (2007). Impact of blood parasites on immunoglobulin leve and parental effort: a medication field experiment on a wild passerine. Functional Ecology 21, 125-133.

Valkiūnas, G. (2005). Avian Malaria Parasites and other Haemosporidia. CRC Press, Boca Raton, Florida, USA.

Valkiūnas, G., Bairlein, F., Iezhova, T. A. and Dolnik, O. V. (2004). Factors affecting the relapse of Haemoproteus belopolskyi infections and the parasitaemia of Trypanosoma spp. in a naturally infected European songbird, the blackcap, Sylvia atricapilla. Parasitology Research 93, 218-222.

Valkiūnas, G., Santiago-Alarcon, D., Levin, I. I., Iezhova, T. A. and Parker, P. G. (2010). A new Haemoproteus species (Haemosporida: Haemoproteidae) from the endemic Galapagos dove Zenaida galapagoensis, with remarks on the parasite distribution, vectors, and molecular diagnostics. Fournal of Parasitology 96, 783-792.

Valkiūnas, G., Palinauskas, V., Ilgūnas, M., Bukauskaité, D., Dimitrov, D., Bernotiené, R., Zehtindjiev, P., Ilieva, M. and Iezhova, T. (2014). Molecular characterization of five widespread avian haemosporidian parasites (Haemosporida), with perspectives on the PCR-based detection of haemosporidians in wildlife. Parasitology Research 113, 2251-2263.

Vargas, H., Lougheed, C. and Snell, H. (2005). Population size and trends of the Galápagos Penguin (Spheniscus mendiculus). Ibis 147, 367-374.

Velando, A. (2002). Experimental manipulation of maternal effort produces differential effects in sons and daughters: implications for adaptive sex ratios in the blue-footed booby. Behavioral Ecology 13, 443-449.

Waldenström, J., Bensch, S., Hasselquist, D. and Östman, Ö. (2004). A new nested polymerase chain reaction method very efficient in detecting Plasmodium and Haemoproteus infections from avian blood. Fournal of Parasitology 90, 191-194.

Wikelski, M., Foufopoulos, J., Vargas, H. and Snell, H. (2004). Galápagos birds and diseases: invasive pathogens as threats for island species. Ecology and Society 9 (issue 1, art. 5) www.ecologyandsociety. org/vol9/iss1/art5.

Zylberberg, M., Derryberry, E. P., Breuner, C. W., MacdougallShackleton, E. A. and Hahn, T. P. (2015). Haemoproteus infected birds have increased lifetime reproductive success. Parasitology 142, 1033-1043. 